\title{
Comparative effectiveness of topical lignocaine nebulization and airway nerve blocks for awake fiber-optic nasal intubation in TM joint ankylosis
}

\author{
Mohamad Sadiq Malla1', Basharat Farooq ${ }^{2}$, Rayees Najib ${ }^{3}$, Sameena Ashraf ${ }^{4}$ \\ ${ }^{1}$ Associate Professor, ${ }^{2,3}$ Assistant Professor, Department of Anaesthesiology and Critical Care, Govt. Medical College, \\ Srinagar, ${ }^{4}$ Assistant Professor (Deputed), Department of Gynaecology and Obstetrics, Govt. Medical College, \\ Baramulla, India
}

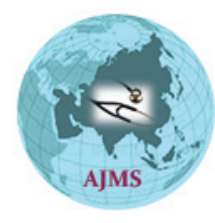

A B S T R A C T

Background: Awake fiber-optic nasal intubation is a gold standard management of difficult airway in temporal mandibular (TM) joint ankylosis. Aims and Objectives: We compared topical lignocaine nebulization with airway nerve blocks for awake fiber-optic nasal intubation in TM joint ankylosis. Materials and Methods: Fifty patients of either gender were randomly allocated into two groups of 25 each. Group I received $10 \mathrm{ml}$ of $2 \%$ lignocaine nebulization over a period for $20 \mathrm{~min}$. Group II received bilateral superior laryngeal nerve block and transtracheal recurrent laryngeal nerve block (each with $2 \mathrm{ml}$ of $2 \%$ lignocaine). Awake fiberoptic bronchoscopy-guided nasal intubation was done in all patients. All the patients received sedation during the procedure. The intubation time, intubating conditions, vocal cord position, cough severity, and degree of patient satisfaction were recorded. Student's t-test was used to analyze parametric data, while the Mann-Whitney U-test was applied to non-parametric data and Fisher's test to categorical data. $\mathrm{P}<0.05$ was considered statistically significant. Results: The time taken for intubation was significantly shorter in Group II [110.2 (14.6) s compared with Group I (211.0 [22.3] s) ( $\mathrm{P}=0.028 \mathrm{ss})$. The intubating conditions and degree of patient comfort were better in Group II compared with Group I. Although all patients were successfully intubated, patient satisfaction was higher in Group II. Conclusion: Airway nerve block is a better way of anesthetizing airway as compared to nebulization for awake fiber-optic nasal intubation. However, nebulization with lignocaine may be an alternative in Access this article online

Website:

http://nepjol.info/index.php/AJMS DOI: 10.3126/ajms.v12i12.39332 E-ISSN: 2091-0576

P-ISSN: 2467-9100

Copyright (c) 2021 Asian Journal of Medical Sciences

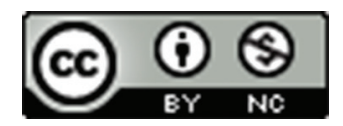

This work is licensed under a Creative Commons Attribution-NonCommercial 4.0 International License. situations where nerve blocks are not feasible or may be used as an adjuvant to nerve blocks.

Key words: Fiber-optic; Lignocaine; Nasal intubation; Nebulization; Nerve blocks

\section{INTRODUCTION}

Intubation during general anesthesia in patients with difficult airway poses a risk to the patient and presents challenges for the anesthesiologists. ${ }^{1,2}$ An unanticipated difficult airway can jeopardize the life of the patient; administering general anesthesia can be disastrous in such situations if the airway is not secured before induction. Awake intubation using a flexible fiber-optic bronchoscope is considered a gold standard, safe, and relatively simple method for intubating the trachea under direct vision in most situations. ${ }^{3}$ The various indications of awake fiber-optic intubation include cervical spine instability, temporomandibular joint ankylosis, facial fractures, partially obstructing laryngeal lesions (e.g. papilloma), and craniofacial abnormalities. ${ }^{4,5} \mathrm{~A}$ pre-requisite for awake fiber-optic nasal intubation is appropriate anesthesia of the nose, oropharynx, larynx, and trachea, to suppress airway reflexes and prevent discomfort during bronchoscopy and intubation. Various techniques are currently used for airway anesthesia including topical anesthesia (with the mucosal application of local anesthetic as a spray, viscous solutions, 
soaked cotton pledgets, and nebulization) or as airway nerve blocks. ${ }^{6}$ Despite the availability of these numerous methods for airway anesthesia, few studies have compared them. Airway nerve blocks are frequently used for awake fiber-optic intubation because they provide rapid and deep anesthesia. Nebulization of local anesthetics is another promising technique, in which the airway is anaesthetized completely without the need for multiple painful injections. Therefore, we compared nerve block, which is considered the standard technique for achieving rapid and effective airway anesthesia, with lignocaine nebulization, which constitutes a simple, painless, and comfortable alternative for anesthetizing the airway, before awake fiber-optic bronchoscopy-guided intubation. When carried out under minimal sedation, these techniques help to allay anxiety so that the patient is more cooperative during the procedure. ${ }^{7}$ This study was conducted to compare the effectiveness of nebulization of lignocaine and airway nerve block for achieving airway anesthesia before awake fiber-optic bronchoscopy-guided nasal intubation. The primary objective was to compare the intubation time of the two techniques, and the secondary objectives were to assess the quality of airway anesthesia, the degree of patient comfort, and post-operative patient satisfaction.

\section{Aims and objectives}

We compared topical lignocaine nebulization with airway nerve blocks for awake fiber-optic nasal intubation in TM joint ankylosis.

\section{MATERIALS AND METHODS}

This analytical cross-sectional study was conducted in dental college, an associated hospital of GMC, Srinagar, over a period of 3 years after receiving approval from the ethical committee of our institution. Fifty adult patients (males and females) of 15-60 years of age with temporomandibular joint ankylosis (mouth opening less than 2 finger breadth) with American Society of Anesthesiologist (ASA) physical status of I-II were randomly divided into two groups of 25 each.

Group I: Received nebulization of $10 \mathrm{ml}$ of $2 \%$ lignocaine over $20 \mathrm{~min}$.
Group II: Received bilateral superior laryngeal nerve block and transtracheal instillation of $2 \mathrm{ml}$ of $2 \%$ lignocaine and $10 \%$ lignocaine spray over the bilateral tonsillar, nasal sponge with $2 \%$ lignocaine.

Patients with mouth opening greater than 2 finger breadth, patients with cardiovascular diseases, airway diseases, allergy, and oral or nasal mass were excluded from the study. All patients received before procedure sedation (injection midazolam $0.02 \mathrm{mg} / \mathrm{kg}$ and fentanyl $1.5 \mathrm{mg} / \mathrm{kg}$ body weight) and anti-sialagogue (injection glycopyrrolate 2.5 microgram $/ \mathrm{kg}$ ). Airway was anesthetized by either lignocaine nebulization or nerve blocks. Adequate local anesthesia was confirmed by the heaviness of the tongue in Group I patients and by hoarseness of voice in Group II patients. A $5.0 \mathrm{~mm}$ flexible fiber-optic bronchoscope with a flexometallic endotracheal tube with an internal diameter of 7.0 or $8.0 \mathrm{~mm}$ (for males and females, respectively) was used. Parameters including intubating conditions, vocal cord position, intubation time, patient comfort, and vital signs were recorded. Vital signs were recorded after 1, 3, 5, and $10 \mathrm{~min}$ of intubation. Intubation time was defined as the time from passing the flexible fiber-optic bronchoscope tip through the nostril to the first reading obtained by the capnograph after endotracheal intubation. Scores for intubating conditions, vocal cord position, and patient comfort (was assessed by cough severity and comfort during and after intubation) are graded as shown in Table 1.

After confirmation of endotracheal intubation by capnography, general anesthesia was achieved with propofol $(2 \mathrm{mg} / \mathrm{kg}, \mathrm{IV})$ and vecuronium bromide $(0.1 \mathrm{mg} / \mathrm{kg}, \mathrm{IV})$. The day after surgery, a post-operative assessment was done to assess adverse effects such as hoarseness, sore throat, and unpleasant memories.

\section{Statistical analyses}

Sample size was calculated by taking the previous data by Gupta et al., into consideration. The required sample size was 50 patients, with power more than $80 \%$ and alpha error of $0.05 \%$. The statistical tests used were Student's t-test for parametric data, the Mann-Whitney U-test for non-parametric data, and Fisher's test for categorical data. The normality of the data was checked using the Shapiro-Wilk test. Continuous variables are expressed as

\begin{tabular}{|c|c|c|c|c|c|}
\hline \multirow{2}{*}{ Grade } & \multirow{2}{*}{$\begin{array}{l}\text { Intubating } \\
\text { conditions }\end{array}$} & \multirow[t]{2}{*}{ Vocal cord position } & \multicolumn{3}{|c|}{ Patient comfort indices } \\
\hline & & & Cough severity & Comfort during intubation & Post intubation assessment \\
\hline Grade 1 & Optimal & Glottis open & No cough & No reaction & Cooperative \\
\hline Grade 2 & Suboptimal & Glottis partially open & $<2$ coughs & Grimacing & Minimal resistance \\
\hline Grade 3 & Difficult & Glottis closed & $3-5$ coughs & Verbal objection & Severe resistance \\
\hline Grade 4 & Failure & & $>5$ coughs & Defensive movements & \\
\hline
\end{tabular}


mean (SD) and categorical variables as proportions (\%). $\mathrm{P}<0.05$ was considered to be statistically significant. The statistical evaluation was done using SPSS software (ver. 20.0; IBM Corp., USA).

\section{RESULTS}

Demographic data were similar between the two groups. There was no significant difference between the two groups with respect to age, sex, body weight, or ASA physical status. The groups were also comparable in terms of airway difficulty, as assessed by modified

Mallampati grade and thyromental distance. However, intubation time in Group II is lesser as compared with Group I and is statistically significant, as shown in Table 2. All patients in both groups were intubated successfully. The mean intubation time for Group II (110.2 [14.7] s) was shorter than that for Group I (209 [22.2] s) ( $\mathrm{P}=0.026)$ [Table 2]. The intubating conditions for Group II were better than those for Group I ( $\mathrm{P}=0.001)$. Twenty-three patients in Group II had optimal intubating conditions compared with only two in Group I. Vocal cord position was also more optimal for intubation in Group II compared with Group I ( $\mathrm{P}=0.002)$. Patient comfort during intubation, as assessed by cough severity $(\mathrm{P}=0.001)$ and intubation comfort scores $(\mathrm{P}=0.012)$, was higher in Group II than in Group I. Similarly, patient tolerability of endotracheal intubation, assessed post-intubation, was significantly higher in Group II than in Group I ( $\mathrm{P}=0.001)$, as shown in Table 3. Post-operative patient satisfaction scores for Group II were higher than those for Group I. In Group II,
23 patients rated their experience of awake fiber-optic intubation as excellent or good and none rated it as poor; however, in Group I, two patients rated the experience as poor and none rated it as excellent. The incidence rates of adverse effects, such as post-operative sore throat, hoarseness of voice, and unpleasant memories, did not differ significantly between the two groups.

\section{DISCUSSION}

Recent advances in the field of anesthesia have resulted in significant improvements in various aspects of airway management. Since the invention of the flexible fiber-optic bronchoscope in 1966 by Dr. Ikeda et al., ${ }^{9}$ and its subsequent use for endotracheal intubation by Dr. Murphy in 1967, ${ }^{10}$ regional anesthesia for the airway has not only rendered awake fiber-optic intubation comfortable and acceptable for patients, but has also afforded anesthesiologists better control over intubation conditions. Several authors have compared different airway anesthesia techniques. In 1990, Webb et al., ${ }^{11}$ compared transcricoid lignocaine injection with use of the spray-as-you-go technique for awake fiberoptic bronchoscopy in 70 adult patients. In 1992, Graham et al., ${ }^{12}$ compared three different methods of providing airway anesthesia during fiber-optic bronchoscopy in 53 patients. In 2000, Kundra et al., ${ }^{13}$ compared nebulized lignocaine $4 \%$ with combined regional nerve block for awake fiberoptic nasotracheal intubation in 48 adult patients. Airway nerve blocks are considered a gold standard and include glossopharyngeal nerve blocks, which anesthetize the oropharynx and block the gag reflex; bilateral superior laryngeal nerve blocks, which anesthetize the larynx above

\section{Table 2: Comparison of demographic characteristics between two groups}

\begin{tabular}{lccc}
\hline Patient parameters & Group I & Group II & P value \\
\hline Age $(\mathrm{yr})$ & $44(10)$ & $44(10)$ & 0.732 \\
Sex $(\mathrm{M} / \mathrm{F})$ & $13 / 12$ & $14 / 11$ & 0.604 \\
Weight $(\mathrm{kg})$ & $64.7(8.1)$ & $65.9(11.3)$ & 0.657 \\
ASA physical status $1 / 2$ & $22 / 3$ & $21 / 4$ & 0.366 \\
Modified Mallampati grade $3 / 4$ & $4 / 21$ & $3 / 22$ & 0.264 \\
Thyromental distance $(\mathrm{cm})(>6.5 / 6-6.5 /<6)$ & $2 / 2 / 21$ & $3 / 2 / 20$ & 0.362 \\
Intubation time (seconds) & $209.0(22.2)$ & $110.2(14.7)$ & 0.026 \\
\hline Data are presented as mean (SD) or number. ASA: American Society of Anesthesiologists & &
\end{tabular}

Table 3: Comparison of intubation characteristics between two groups

\begin{tabular}{|c|c|c|c|c|c|c|c|c|}
\hline & \multicolumn{2}{|c|}{ Grade 1} & \multicolumn{2}{|c|}{ Grade 2} & \multicolumn{2}{|c|}{ Grade 3} & \multicolumn{2}{|c|}{ Grade 4} \\
\hline & I & II & I & II & I & II & I & II \\
\hline Intubation conditions & 2 & 23 & 12 & 2 & 11 & 0 & 0 & 0 \\
\hline Vocal cord position & 1 & 20 & 14 & 5 & 10 & 0 & 0 & 0 \\
\hline Cough severity & 1 & 18 & 22 & 4 & 2 & 3 & 0 & 0 \\
\hline Intubation comfort & 1 & 22 & 21 & 3 & 3 & 0 & 0 & 0 \\
\hline Post-intubation assessment & 4 & 23 & 20 & 2 & 1 & 0 & 0 & 0 \\
\hline Patient satisfaction & 0 & 10 & 12 & 13 & 10 & 2 & 3 & 0 \\
\hline
\end{tabular}


the level of the vocal cords and block glottic closure reflex; and transtracheal nerve blocks, which anesthetize the trachea and larynx below the level of the vocal cords and abolish the cough reflex. Airway nerve block provides rapid and deep anesthesia with only small doses of local anesthetic, but a thorough knowledge of regional anatomy, as well as operator skill and experience, is required for correct application. The procedure also involves a risk of accidental intravascular injection and nerve injury, and airway nerve block is not feasible when there is distorted anatomy, such as in cases of massive neck swelling, traumatic injury to the head and neck, and local infection. ${ }^{6,7}$ Nebulization of local anesthetics is another technique that deposits fine droplets of local anesthetic directly over the mucosa, thus anesthetizing it and obviating the need for multiple painful injections. Furthermore, this technique requires less detailed knowledge of anatomy, less specialist skills, and less experience; it can also be used in cases of massive neck swelling where nerve block cannot be performed. However, it has some disadvantages including the requirement for large doses of local anesthetic (due to wastage during administration), a higher chance of failure, and a delayed onset of action. In this study, we used $10 \mathrm{ml}$ of $2 \%$ lignocaine $(200 \mathrm{mg})$ for nebulization in adult patients, based on a previous study by Sutherland et al., ${ }^{14}$ who found that lignocaine nebulization using a median dose of $512 \mathrm{mg}$ caused toxicity at a plasma concentration above $5 \mu \mathrm{g} / \mathrm{ml}$ in two of their patients, but that a dose of $370 \mathrm{mg}$ did not lead to toxicity. Gjonaj et al., ${ }^{15}$ compared $8 \mathrm{mg} / \mathrm{kg}$ and $4 \mathrm{mg} / \mathrm{kg}$ lignocaine for nebulization and found both doses to be safe, while Parkes et al., ${ }^{6}$ who used $6 \mathrm{mg} / \mathrm{kg}$ lignocaine, did not observe a maximum plasma lignocaine level exceeding $0.45 \mathrm{mg} / \mathrm{L}$ in any of their subjects. Because there was no way to measure plasma lignocaine concentrations in our study, we limited the maximum dose of lignocaine to $200 \mathrm{mg}$. A higher concentration of lignocaine would have reduced the total effective volume reaching the airway mucosa if the dose remained the same. Hence, we deemed it sufficient to use a maximum concentration of lignocaine of $2 \%$, in a possible volume of $10 \mathrm{ml}$, to produce effective anesthesia without causing lignocaine toxicity. In our study, there was no failure of intubation in either group. The mean intubation time was significantly shorter in the nerve block group; this was similar to the findings of Gupta et al., ${ }^{8}$ who reported a mean intubation time of 123 (46.7) $\mathrm{s}$ in a nerve block group and 200.4 (72.4) s in a nebulization group $(\mathrm{P}=0.047)$. However, Reasoner et al., ${ }^{16}$ found no significant difference in intubation time between nerve block and topical anesthesia groups, and in both of their groups, the intubation time was longer than in any other study. In contrast to our study, the degree of operator skill with awake fiber-optic intubation was not specified in any previous report. In our study, the intubating conditions were better in Group II compared with Group I, similar to the studies of Webb et al., ${ }^{11}$ and Graham et al. ${ }^{12}$ However, Reasoner et al., ${ }^{16}$ and Gupta et al., ${ }^{8}$ found no significant difference in intubating conditions between the groups. It should be noted that no standardized scale for evaluating intubating conditions was used in the previous studies, so we could not directly compare their intubating conditions with those of our study. We compared patient comfort between our two study groups according to cough severity and intubation comfort scores during and after intubation; patient comfort was higher in the nerve block group. This can be attributed to the deposition of local anesthetic in the vicinity of the nerves. However, during nebulization, the local anesthetic is deposited over the mucosa, that is, away from the nerves, so a larger amount of local anesthetic is needed. Furthermore, unpredictable deposition amounts due to wastage can lead to patchy, less effective aesthesia. Gupta et al., ${ }^{8}$ also observed significant coughing in their nebulization group compared with a nerve block group.

\section{CONCLUSION}

This study revealed that airway anesthesia using airway nerve blocks is superior to lignocaine nebulization for awake fiber-optic bronchoscopy-guided nasotracheal intubation, in terms of ease of intubation and patient comfort and satisfaction. Nevertheless, lignocaine nebulization may be used as an alternative technique for airway anesthesia when a nerve block is not feasible because we observed no case of failure of awake fiber-optic intubation and no complications related to nebulization.

\section{ACKNOWLEDEGMENT}

The authors take this opportunity to thank the Department of Dentistry and Department of Anaesthesiology and Critical Care, Govt. Medical College, Srinagar, for their wholehearted support for this study.

\section{REFERENCES}

1. Benumof JL. Management of the difficult adult airway. With special emphasis on awake tracheal intubation. Anesthesiology. 1991;75(6):1087-1110.

https://doi.org/10.1097/00000542-199112000-00021

2. Barash PG, Cullen BF and Stoelting RK. Clinical Anesthesia. $5^{\text {th }}$ ed. Philadelphia, PA: Lippincott Williams and Wilkins; 2006. p. 621-30.

3. Panchabhai TS and Mehta AC. Historical perspectives of bronchoscopy. Connecting the dots. Ann Am Thorac Soc. 2015;12(5):631-41.

4. Yrigoyen E and Fujikawa YF. Flexible fiberoptic bronchoscopy. Anesthesia, technique and results. West J Med. 1975;122(2): 117-122.

5. Díaz-Jimenez JP and Rodriguez AN. Interventions in Pulmonary 
Medicine. Houston, Springer. 2013, pp 13-31.

6. Parkes SB, Butler CS and Muller R. Plasma lignocaine concentration following nebulization for awake intubation. Anaesth Intensive Care. 1997;25(4):369-371. https://doi.org/10.1177/0310057x9702500408

7. Dhasmana SC. Nasotracheal fiberoptic intubation: patient comfort, intubating conditions and hemodynamic stability during conscious sedation with different doses of dexmedetomidine. J Maxillofac Oral Surg. 2014;13(1):53-58.

https://doi.org/10.1007/s12663-012-0469-0

8. Gupta B, Kohli S, Farooque K, Jalwal G, Gupta D, Sinha S, et al. Topical airway anesthesia for awake fiberoptic intubation: Comparison between airway nerve blocks and nebulized lignocaine by ultrasonic nebulizer. Saudi J Anaesth. 2014;8(Suppl 1):S15-S19.

https://doi.org/10.4103/1658-354x.144056

9. Ikeda $\mathrm{S}$, Yanai $\mathrm{N}$ and Ishikawa $\mathrm{S}$. Flexible bronchofiberscope. Keio J Med. 1968;17(1):1-16.

https://doi.org/10.2302/kjm.17.1

10. Murphy P. A fibre-optic endoscope used for nasal intubation. Anaesthesia. 1967;22:489-491.

https://doi.org/10.1111/j.1365-2044.2010.06535.x

11. Webb AR, Fernando SS, Dalton HR, Arrowsmith JE, Woodhead MA and Cummin AR. Local anaesthesia for fibreoptic bronchoscopy: Transcricoid injection or the "spray as you go" technique? Thorax. 1990;45(6):474-477.

https://doi.org/10.1136/thx.45.6.474

12. Graham DR, Hay JG, Clague J, Nisar M and Earis JE. Comparison of three different methods used to achieve local anesthesia for fiberoptic bronchoscopy. Chest. 1992;102(3):704707.

https://doi.org/10.1378/chest.102.3.704

13. Kundra P, Kutralam S and Ravishankar M. Local anaesthesia for awake fibreoptic nasotracheal intubation. Acta Anaesthesiol Scand. 2000;44(5):511-516. https://doi.org/10.1034/j.1399-6576.2000.00503.x

14. Sutherland AD, Santamaria JD and Nana A. Patient comfort and plasma lignocaine concentrations during fibreoptic bronchoscopy. Anaesth Intensive Care. 1985;13(4):370-374. https://doi.org/10.1177/0310057x8501300406

15. Gjonaj ST, Lowenthal DB and Dozor AJ. Nebulized lidocaine administered to infants and children undergoing flexible bronchoscopy. Chest. 1997;112(6):1665-1669. https://doi.org/10.1378/chest.112.6.1665

16. Reasoner DK, Warner DS, Todd MM, Hunt SW and Kirchner J. A comparison of anaesthetic techniques for awake intubation in neurosurgical patients. J Neurosurg Anaesthesiol. 1995;7(2):94-99.

\section{Authors Contribution:}

MSM - Concept and design of study, prepared first draft of manuscript, and statistically analyzed and interpreted; BF - Concept, coordination, and revision of manuscript; RN - Concept coordination, review of literature, and manuscript preparation; SA - Interpreted the result reviewed the literature and prepared the manuscript.

\section{Work attributed to:}

Department of Dentistry, Govt. Medical College, Jammu, India.

\section{Orcid ID:}

Mohammad Sadiq Malla - (i) http://orcid.org/0000-0003-2189-6320

Basharat Farooq - it http://orcid.org/0000-0001-5444-9717

Rayees Najib - (D) http://orcid.org/0000-0002-1656-2556

Sameena Ashraf - (1) http://orcid.org/0000-0002-6494-6896

Source of Funding: None, Conflicts of Interest: None. 